\title{
Subclinical Cushing's Syndrome
}

revisão

MASSIMO TERZOLO SILVIA BOVIO

ANNA PIA

Giangiacomo Osella GIORGIO BORRETTA

ALbERTO ANGELI GIUSEPPE REIMONDO

Dipartimento di Scienze Cliniche e Biologiche, Medicina Interna I,

A.S.O. San Luigi, Università di

Torino (MT, SB, GO, AA \& GR), and Endocrinologia, A.O.

Santa Croce e Carle, Cuneo (AP \& GB), Italy.

Recebido em 14/08/07 Aceito em 19/08/07

\section{ABSTRACT}

Subclinical Cushing's syndrome (CS) is attracting increasing interest since the serendipitous discovery of an adrenal mass has become a rather frequent event owing to the routine use of sophisticated radiologic techniques. Cortical adenoma is the most frequent type of adrenal incidentaloma accounting for approximately $50 \%$ of cases in surgical series and even greater shares in medical series. Incidentally discovered adrenal adenomas may secrete cortisol in an autonomous manner that is not fully restrained by pituitary feedback, in 5 to $20 \%$ of cases depending on study protocols and diagnostic criteria. The criteria for qualifying subclinical cortisol excess are controversial and presently there is no consensus on a gold standard for the diagnosis of this condition. An increased frequency of hypertension, central obesity, impaired glucose tolerance, diabetes and hyperlipemia has been described in patients with subclinical CS; however, there is still no clear demonstration of the long-term complications of this condition whose management remains largely empirical. Either adrenalectomy or careful observation associated with treatment of the metabolic syndrome have been suggested as treatment options. (Arq Bras Endocrinol Metab 2007;51/8:1272-1279)

Keywords: Adrenal adenoma; Cortisol; Incidentaloma; Subclinical Cushing's syndrome

\section{RESUMO}

Síndrome de Cushing Subclínica.

A síndrome de Cushing subclínica (SCS) tem atraído interesse cada vez maior desde que a descoberta casual de uma massa adrenal se tornou um evento freqüente devido ao emprego rotineiro de técnicas sofisticadas de imagem. O adenoma cortical é o tipo mais freqüente de incidentaloma adrenal, correspondendo a cerca de $50 \%$ dos casos em séries cirúrgicas e até mais do que isso em séries médicas. Adenomas adrenais descobertos incidentalmente podem secretar cortisol de maneira autônoma ou não controlada totalmente pelo feedback hipofisário, em 5 a $20 \%$ dos casos, dependendo do protocolo de estudo e dos critérios diagnósticos. Os critérios para qualificar um excesso subclínico de cortisol são controversos e atualmente não existe consenso a respeito de "padrão ouro" para o diagnóstico dessa condição. Em pacientes com SCS, tem sido descrita uma freqüência elevada de hipertensão, obesidade central, intolerância à glicose, diabetes e hiperlipemia; entretanto, ainda não existe uma evidente demonstração de complicações a longo prazo dessa condição, cujo manejo permanece amplamente empírico. Tanto a adrenalectomia como a observação cuidadosa, associada com o tratamento da síndrome metabólica, têm sido sugeridos como opções terapêuticas. (Arq Bras Endocrinol Metab 2007;51/8:1272-1279)

Descritores: Adenoma adrenal; Cortisol; Incidentaloma; Síndrome de Cushing subclínica 


\section{DEFINITION}

S UBCLINICAL CUSHING's SYNDROME occurs in patients bearing clinically inapparent adrenal adenoma secreting cortisol in an autonomous and unregulated way that is not fully restrained by pituitary feedback. Although the term "preclinical" Cushing's syndrome has been proposed previously, the term "subclinical" Cushing's syndrome describes more accurately this condition, not implying any assumption on the further development of a clinically overt syndrome. Since the prevalence of overt Cushing's syndrome caused by adrenal adenoma in the general population is exceedingly lower than the prevalence of subclinical Cushing's syndrome in patients with clinically non-functioning adrenal adenoma, it is rather inappropriate to consider subclinical Cushing's syndrome as an early stage of development of overt hypercortisolism (1). Recently, the new definition of "subclinical autonomous glucocorticoid hypersecretion" has been proposed to identify this endocrine disorder (2) even if autonomous cortisol secretion may not be always associated with cortisol excess.

Two criteria should be met to define subclinical Cushing's syndrome. First, the patient should not present a clear Cushing phenotype and, second, the patient should bear an adrenal mass detected serendipitously (3). The first criterion is critical since it depends largely on individual clinical judgment and personal practice. The physicians who have less clinical experience with Cushing's syndrome might overlook (mild) signs of hypercortisolism since some of them, such as facial fullness and central obesity, are specific and of common observation. Thus, it is difficult to decide whether these signs may be attributable to an underlying occult hypercortisolism or are manifestations of the metabolic syndrome. Concerning the second point, the concept of subclinical hypercortisolism may be extended also to patients bearing pituitary incidentaloma (4) and patients who are over-replaced with adrenal steroid therapy (5); anyway, these issues are beyond the scope of this review. Moreover, subtle glucocorticoid excess may also be demonstrated in some patients who have non-adenomatous adrenal masses, such as adrenocortical carcinoma (6) and, exceptionally, myelolipoma (7).

\section{DIAGNOSIS}

Although the pathophysiologic concept of autonomous cortisol secretion sustained by an adrenal adenoma is straightforward, demonstration of subclinical Cushing's syndrome is extremely difficult in practice. In fact, the standard biochemical tests used to screen Cushing's syndrome are generally ill-suited to the assessment of patients who have no, or only mild, signs of cortisol excess $(1,8)$. In this clinical setting, the $a$ priori probability of subclinical Cushing's syndrome is roughly comparable with the false-positive rate of the tests used for screening $(1,8)$. In the absence of reliable clinical clues it is indeed challenging to distinguish between true-positive and false-positive test results. Moreover, many tests used to study the HPA axis do not have sufficient sensitivity to recognize a very mild degree of cortisol excess. This is the case for the determination of urinary free cortisol (UFC) that has also the drawback of a remarkable daily variation in either cortisol excretion in the urine or daily urine output (the latter problem is amplified by the difficulty in obtaining complete urine collections) (9).

The reported prevalence of subclinical Cushing's syndrome among patients with adrenal incidentaloma ranges from $5 \%$ to $20 \%(2,3,11-17)$. The sources of this heterogeneity may be found in the different work-up protocols and variable criteria used to define subclinical cortisol excess as well as in different inclusion criteria and size of the reported series (table 1). Methodological limits add to the intrinsic biological problems associated with identification of subclinical cortisol excess thus explaining the great uncertainty surrounding this entity. A number of alterations of the HPA axis have been associated to clinically inapparent adrenal adenomas (figure 1).

Blunting of the circadian rhythm of cortisol seems more frequent than elevation of UFC and this confirms the view that derangement of the daily secretory pattern of cortisol is an early marker of (subclinical) hypercortisolism $(12,13,17)$. Also low to unde-

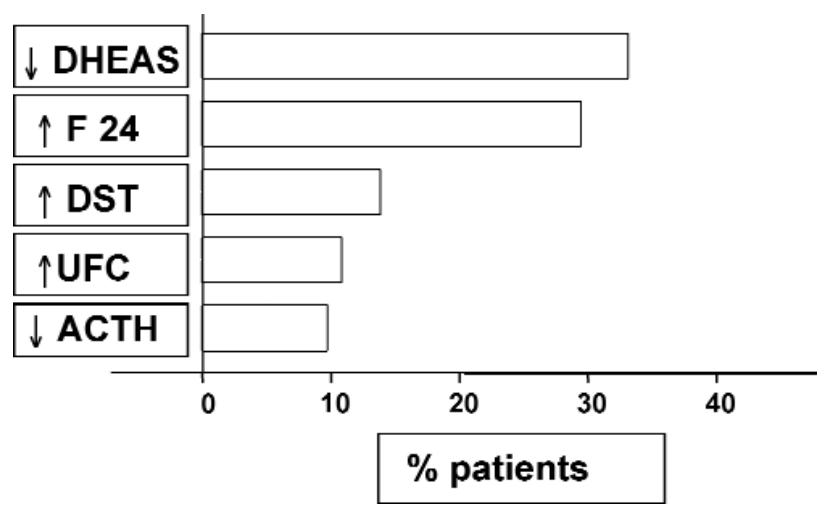

Figure 1. Alterations of the HPA axis observed in 210 patients with clinically inapparent adrenal adenoma. Association of at least two alterations was found in $17.9 \%$ of patients. [Terzolo et al., ref. 3] 
Table 1. Alterations of the hypothalamic-pituitary-adrenal axis and frequency of subclinical Cushing's syndrome in patients with adrenal incidentaloma.

\begin{tabular}{|c|c|c|c|c|c|}
\hline AUTHOR, YEAR & $\begin{array}{l}\text { PATIENTS } \\
\text { (no.) }\end{array}$ & $\begin{array}{l}\text { ELEVATED } \\
\text { UFC }\end{array}$ & $\begin{array}{c}\text { REDUCED } \\
\text { ACTH }\end{array}$ & $\begin{array}{c}\text { NON SUPPRESSION } \\
\text { AFTER DST }\end{array}$ & $\begin{array}{l}\text { FREQUENCY } \\
\text { OF SCS }\end{array}$ \\
\hline Virkkala '89 & 20 & NA & NA & NA & $25 \%$ \\
\hline Hensen '90 & 13 & $0 \%$ & $15 \%$ & $23 \%$ & $8.0 \%$ \\
\hline Herrera '91 & 172 & NA & NA & $1.1 \% *$ & $1.1 \%$ \\
\hline Jockenhövel '92 & 18 & $5.5 \%$ & $5.5 \%$ & $50 \% *$ & $5.5 \%$ \\
\hline Reincke '92 & 66 & $1.5 \%$ & $7.5 \%$ & $12 \% * *$ & $12 \%$ \\
\hline Aso '92 & 210 & NR & NR & NR & $3.3 \%$ \\
\hline Kobayashi '93 & 14 & $50 \% \#$ & NR & $50 \% *$ & $50 \%$ \\
\hline Siren '93 & 36 & NA & NA & NA & $5.5 \%$ \\
\hline Caplan '94 (20) & 26 & NA & $11 \%$ & NA & $11 \%$ \\
\hline Osella '94 & 45 & $2 \%$ & NA & $15 \%$ & $16 \%$ \\
\hline Seppel '94 (31) & 52 & NA & NA & NA & $1.9 \%$ \\
\hline Flecchia '95 & 24 & $21 \%$ & $25 \%$ & $17 \%$ & $29 \%$ \\
\hline Ambrosi '95 & 32 & $12 \%$ & $3 \%$ & $14 \%$ & $12 \%$ \\
\hline Bencsik '96 & 63 & NA & NA & NA & $21 \%$ \\
\hline Bardet '96 & 35 & $11 \%$ & $21 \%$ & $13 \% *$ & $8.5 \%$ \\
\hline Linos '96 & 57 & $0 \%$ & NR & $13 \%$ & $8.8 \%$ \\
\hline Bastounis '97 & 86 & NA & NA & NA & $3.5 \%$ \\
\hline Bondanelli '97 & 38 & $2.6 \%$ & $18 \%$ & $10 \% * *$ & $10 \%$ \\
\hline Kasperlik-Zaluska '97 & 208 & $5.2 \% \#$ & $34 \%$ & $3.0 \% * *$ & $2.9 \%$ \\
\hline Proye '9 & 103 & NR & NR & NR & $0 \%$ \\
\hline Terzolo '98 & 53 & $7.5 \%$ & $9.4 \%$ & $17 \%$ & $6.0 \%$ \\
\hline Murai '99 & 59 & NR & NR & NR & $1.7 \%$ \\
\hline Tutuncu '99 & 33 & NR & NR & NR & $6.1 \%$ \\
\hline Rossi '00 & 65 & $17 \%$ & $23 \%$ & $25 \%$ & $18.4 \%$ \\
\hline Mantero '00 & 1004 & $11 \%$ & $15 \%$ & $10 \%$ & $9.2 \%$ \\
\hline Morioka ‘00 & 56 & $3.6 \% \#$ & $7.1 \%$ & $11 \%$ & $12.5 \%$ \\
\hline Favia '00 & 158 & NR & NR & $5.1 \%$ & $5.1 \%$ \\
\hline Tanabe '01 & 38 & NR & $26 \%$ & $47 \% \otimes$ & $47 \%$ \\
\hline Midorikawa ‘01 & 20 & $20 \% \#$ & $15 \%$ & $25 \%$ & $20 \%$ \\
\hline Grossrubatscher '01 & 53 & $4.0 \% \#$ & $15 \%$ & $11 \%$ & $5.7 \%$ \\
\hline Valli '01 & 31 & $61 \%$ & $26 \%$ & $39 \%$ & $31.4 \%$ \\
\hline Barzon '02 & 284 & NR & NR & NR & $11.3 \%$ \\
\hline Bulow '02 & 381 & $0.8 \%$ & NR & $1.0 \%$ & $1.0 \%$ \\
\hline
\end{tabular}

DST: dexamethasone suppression test, NA: not available, NR: not reported, SCS: subclinical Cushing's syndrome

DST is the 1-mg overnight test with a threshold for cortisol suppression at $5.0 \mu \mathrm{g} / \mathrm{dL}$ unless specified otherwise

* $2 \mathrm{mg} \mathrm{DST}$; * $8 \mathrm{mg} \mathrm{DST}$; ${ }^{\otimes}$ Threshold for cortisol suppression at $3.0 \mu \mathrm{g} / \mathrm{dL}$; \# Urinary 17-hydroxycorticosteroid.

tectable ACTH levels have been frequently reported (11-13) even if technical problems associated with measurement of ACTH concentrations close to the detection limits of the assay affect the utility of ACTH determination to demonstrate functional autonomy of an adrenal adenoma (9). Use of CRH test does not seem to add significant information to baseline ACTH levels $(11,12,17,18)$. Low dehydroepiandrosterone sulfate (DHEAS) levels is the most frequent hormonal alteration $(11,17,19-22)$ and was thought to result from suppression of ACTH secretion by autonomous cortisol production $(17,19)$. However, it is presently unclear whether a reduction in DHEAS secretion may be interpreted as a marker of functional autonomy $(17,18,20,22)$. It has to be considered that the agerelated decline in DHEAS secretion may hamper recognition of reduced DHEAS concentrations in an aged population (17).

Not surprisingly, the dexamethasone suppression test (DST) has been widely employed to unmask subtle abnormalities of cortisol secretion in patients with adrenal incidentaloma. It was found that cortisol concentrations after DST are in negative correlation with basal ACTH levels and in positive correlation 
with both midnight cortisol concentrations and size of the incidentally discovered adrenal mass (22). Howev$\mathrm{er}$, the results of the published studies are not readily comparable since different protocols and cut-off values to define cortisol suppression have been used (8). The classical 2-day-dexamethasone test is considered more accurate than the overnight 1-mg dexamethasone suppression test (23), but it is more difficult to perform in the clinical practice. The recent NIH state-of-the-science conference panel on adrenal incidentaloma has recommended the overnight l-mg DST to screen for autonomous cortisol secretion adopting the traditional cortisol threshold of $5 \mu \mathrm{g} / \mathrm{dL}(138 \mathrm{nmol} / \mathrm{L})$ to define adequate suppression (2). However, some authors suggest that the proposed cut-off is too high to detect slight cortisol excess and has the drawback of a high rate of false negative results (24). This argumentation comes from the observation that in most healthy subjects cortisol is barely detectable following $\mathrm{l} \mathrm{mg}$ dexamethasone $(24,25)$. The consensus statement on the diagnosis of Cushing's syndrome has indeed proposed a cortisol cut-off level lower than 1.8 $\mathrm{mg} / \mathrm{dL}(50 \mathrm{nmol} / \mathrm{L})(9)$. However, the use of lower cut-off values is inevitably associated with an increased rate of false positive results. The suggestion of giving higher dexamethasone doses, such as $3 \mathrm{mg}$ or $8 \mathrm{mg}$, has not gained widespread acceptance and has not added significant insight to solve this controversy. At present, the recommendation to use the overnight 1 mg DST seems sound since this test has been extensively employed for screening purposes, whereas there is less experience with the use of high-dose dexamethasone tests in settings other than the differential diagnosis of patient with proven Cushing's syndrome.

To circumvent the problem of false positive results, it has been advocated that two concomitant abnormal results in the tests used for screening should be demonstrated to diagnose subclinical Cushing's syndrome $(11,12,26)$. Many combinations of abnormal tests may be demonstrated when the HPA axis is studied in detail $(10-12,17)$, and it remains difficult, even with this approach, to define subclinical Cushing's syndrome.

Functional autonomy of clinically inapparent adrenal adenomas may be demonstrated in vivo by iodocholesterol scintigraphy with a typical imaging pattern of unilateral tracer uptake in the adenoma and absent uptake in the contralateral adrenal gland. Several studies have correlated the scintigraphic pattern of unilateral uptake with cortisol hypersecretion by the adenoma and consequent pituitary ACTH suppression $(15,21,26)$. Scintigraphic uptake may represent a very early sign of functional autonomy, because NP-59 uptake on the side of the mass without visualization of the contralateral adrenal gland (concordant uptake) occurs even with normal biochemical tests $(12,17)$. An alternative explanation is that the increased uptake simply reflects the presence of enlarged adrenal tissue (17). Notwithstanding this uncertainty in the interpretation, adrenal scintigraphy has become progressively less popular because it is time-consuming, expensive and not widely available.

The current uncertainty on what strategy is best suited to detect adrenal cortical autonomy might be solved by finding at what point cortisol excess becomes clinically significant causing clinical morbidity. We are presently unable to answer this question because we do not know to which extent subclinical Cushing's syndrome may affect patients' health and may affect life expectancy (27).

\section{NATURAL HISTORY}

Since many patients with clinically nonfunctioning incidentaloma are exposed to a chronic, even if only minimal to mild, cortisol excess, it is biologically plausible to anticipate that they should suffer, at least to some extent, from the classic long-term consequences of overt Cushing's syndrome, such as arterial hypertension, obesity, or diabetes $(8,27,28)$ (figures 2 and $3)$. Several data from autopsy series $(2,15)$, cross-sectional studies $(12,26)$ and case-control studies $(29,30)$ consistently point to an association between clinically inapparent adrenal adenoma and some manifestations of the metabolic syndrome (table 2). In a multi-institutional study of 1,004 patients with incidentally detected adrenal masses, the prevalence of arterial hypertension, diabetes, and obesity was remarkably high among patients with adrenal adenomas, with a rate of $41 \%, 10 \%$, and $28 \%$, respectively (30).

In a cross-sectional study, we have previously demonstrated that nonobese, normoglycemic patients who had clinically inapparent adrenal adenoma had frequent occurrence of impaired glucose tolerance (IGT), elevated blood pressure, and reduced insulin sensitivity compared with matched controls (29). Such alterations were also found in patients who had nonfunctioning adenoma even if metabolic alterations were more pronounced in the patients who qualified for subclinical Cushing's syndrome. A significant inverse correlation was found between the values of an OGTT-derived insulin sensitivity index and midnight serum cortisol concentrations (29). 


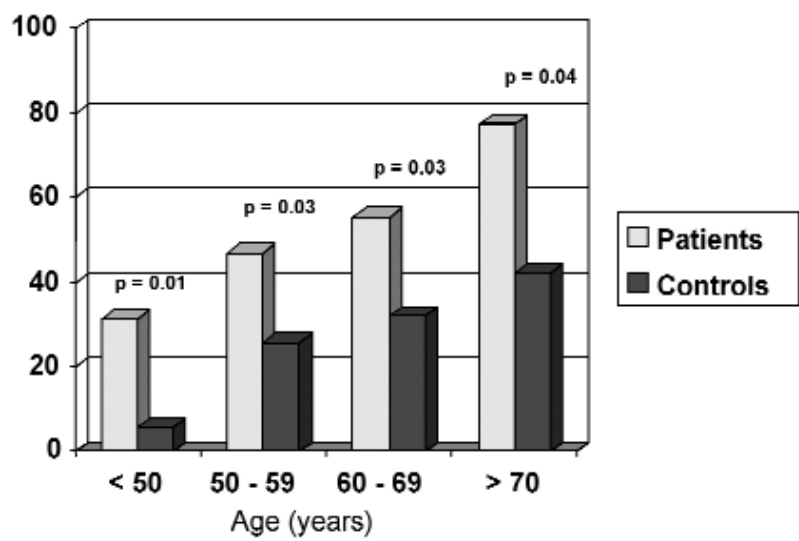

Figure 2. Prevalence of hypertension in patients with non functionally adrenal adenoma. [Data from the National Italian Study Group of adrenal tumors, 2004]

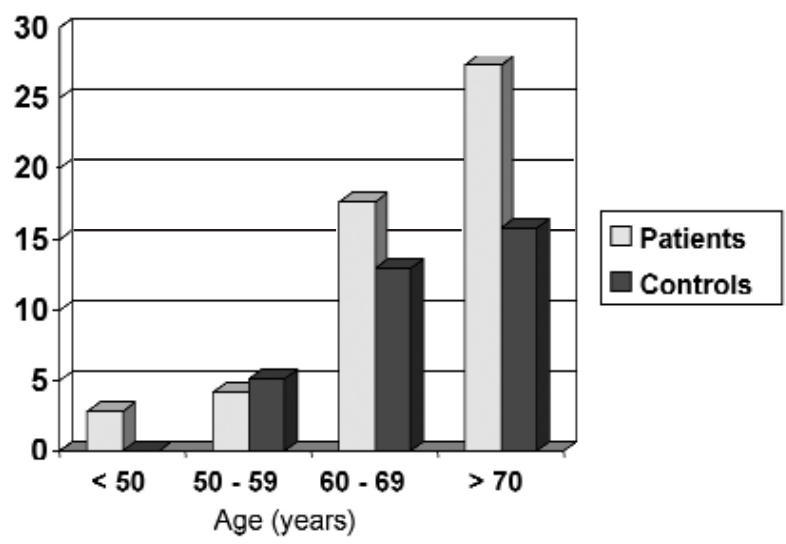

Figure 3. Prevalence of diabetes in patients with non functionally adrenal adenoma. [Data from the National Italian Study Group of adrenal tumors, 2004]

Table 2. Characteristics of the metabolic syndrome described in patients with clinically inapparent adrenal adenoma (highlighted in bold).

\begin{tabular}{l}
\hline Systolic and diastolic hypertension \\
Hyperinsulinemia / Insulin resistance \\
\hline Endotelial dysfunction \\
Low HDL cholesterol \\
Elevated triglycerides \\
LDL remnants \\
\hline Elevated fibrinogen \\
Hypercoagulability \\
\hline Increase of PCR and other inflammatory markers \\
\hline Microalbuminuria \\
\hline Non-dipping BP pattern \\
\hline Increase of uric acid \\
\hline Left ventricular hypertrophy \\
Accelerated atherosclerosis \\
\hline
\end{tabular}

In a recent multi-institutional retrospective study of 210 patients with clinically inapparent adrenal adenoma, we have observed hypertension in $53.8 \%$ of patients, obesity in $21.4 \%$ and hyperglycemia in $22.4 \%$, respectively. The patients with elevated midnight serum cortisol concentrations displayed higher fasting glucose and systolic blood pressure than the subjects with normal cortisol levels (30). These data support the view that clinically inapparent adrenal adenomas may be associated with an increased risk of metabolic and cardiovascular diseases (27), and extend the results previously obtained by Tauchmanova et al. (33). They found that 28 of 126 subjects with adrenal incidentaloma, who qualified for subclinical Cushing's syndrome, showed an adverse risk profile compared with matched controls; these patients also showed a significant increment in the carotid intimalmedial thickness (31).

The results of the above-mentioned studies are in an overall agreement and argue in favor of the view that subclinical Cushing's syndrome may be associated with the clinical phenotype of the insulin resistance syndrome. However, the interpretation of these data must be considered with a note of caution. First, it may be not completely correct to generalize results from series gathered in academic centers and, additionally, referral bias is an obvious limit since these studies are not population-based. Second, there is a potential for confounding in the case-control design since an accurate matching between patients and controls for the many factors that may affect cardiovascular risk is difficult to achieve. Third, in none of the studies the assessment of insulin sensitivity was pursued by using the gold standard test, the glucose clamp, even if the surrogate markers employed have been validated previously for epidemiologic studies (32). Fourth, the published series are not large, but protocols are similar, and data are remarkably consistent across studies.

An alternative hypothesis that adrenal incidentaloma may be a consequence rather than cause of the metabolic syndrome could not be ruled out (33); however, a causal link between subclinical Cushing's syndrome and insulin resistance is the most plausible explanation for the available data (27). In this line, the presence of a relationship between elevated midnight cortisol concentration and metabolic or vascular alterations does not establish causality; however, these data are suggesting that midnight serum cortisol may be viewed as a surrogate marker of insulin sensitivity in patients who have clinically inapparent adrenal adenoma (30). 
Even if there is evidence that subclinical Cushing's syndrome may promote development of insulin resistance, that is known to be associated with enhanced all-cause and cardiovascular mortality (34), it is presently unknown whether mortality is increased in patients with clinically inapparent adrenal adenoma, with or without subclinical Cushing's syndrome (28). The scarce available data suggest that most patients with adrenal incidentaloma die of causes not strictly related to the adrenal mass itself but mostly from cardiovascular events, but it is unknown whether the mortality rate is higher than the general population $(35,36)$. Prospective studies of adequate power to address disease-specific or all-cause mortality should address this issue. These studies may be unfeasible, however, if not by means of multi-institutional collaboration, because of the low frequency of disease-specific outcomes.

Osteoporosis is another well-established consequence of overt cortisol excess (9), but data on bone mineral density in patients who have clinically inapparent adrenal adenoma are somewhat controversial (3). Differences in the devices used to estimate bone density and in selection criteria of either patients or controls, along with the small number of subjects studied, are likely explanations for the divergent results. An increased risk of osteoporosis has been documented by the most recent studies that addressed this issue (3740). Moreover, in a recent study an increased prevalence of vertebral fractures in women with subclinical Cushing' syndrome was found, corroborating the notion that even subtle glucocorticoid excess can exert a detrimental effect on bone quality, particularly in condition of estrogen deficiency (41). Longitudinal studies of adequate statistical power are urgently needed to estimate the risk of osteoporotic fractures and their attendant impact on outcome and quality of life.

Evolution of silent hypercortisolism to the overt clinical syndrome occurs rarely, while appearance of silent biochemical alterations was reported in a percentage ranging from $0 \%$ to $11 \%$ across different studies (14) (table 3). It was found that masses of $3 \mathrm{~cm}$ or greater are more likely to develop silent hyperfunction than smaller tumors, and the risk seems to plateau after 3 to 4 years, even if it does not subside completely (35). In other series, no case of evolution from subclinical to overt Cushing was observed $(12,42,43)$ even if several endocrine modifications occurred during follow-up. In some cases, a spontaneous regression of the alterations of the HPA axis may be observed and this finding suggests that cortisol hypersecretion may have a cyclical pattern $(12,43)$.
The interpretation of these follow-up studies is affected by their small sample size, variable length of follow-up, and variable follow-up strategies. The potential for ascertainment bias also should be disclosed, because many of these observations are made in small, retrospective series. Also the issue of the potential progression over time of metabolic derangements that could be attributable to subclinical Cushing's syndrome remains unsolved by the published studies. The currently available evidence does not allow to make any stringent recommendation for periodic hormonal testing. In the NIH state-of-the-science statement, however, it is reported that it is reasonable to repeat hormonal screening by means of the $1 \mathrm{mg}$ DST annually for at least 4 years (2).

\section{MANAGEIMENT GUIDELINES}

Data from randomized trials are lacking to guide the appropriate management of subclinical Cushing's syndrome, thus, the therapeutic approach remains largely empirical. Since an increased frequency of hypertension, central obesity, impaired glucose tolerance, diabetes and hyperlipemia has been described in patients with subtle glucocorticoid excess, the management of clinically inapparent adrenal adenoma may have a great deal to do with cardiovascular prevention (27). However, a clear demonstration of long-term consequences of subclinical Cushing's syndrome is still lacking.

Reasonably, adrenalectomy should be considered for younger subjects (below 40 years of age) and for patients with metabolic derangements and hypertension, or both, of recent onset, or for patients with the metabolic syndrome resistant to medical intervention, or rapidly decompensating $(3,44)$. Steroid replacement therapy after adrenalectomy should be reserved for patients with subclinical Cushing syndrome because of the risk for adrenal insufficiency. Patients undergoing adrenalectomy for non-secreting adrenal adenomas do not usually require chronic postoperative steroid replacement (45). It is difficult, however, to predict the risk of postoperative adrenal insufficiency on the basis of pre-operative data; thus, steroid coverage in the early post-operative period may recommended in all patients after adrenalectomy (8). Steroids should be discontinued after demonstration of an intact HPA axis according to established workup protocols (46).

Although adrenalectomy has been demonstrated to correct the hormonal abnormalities due to 
Table 3. Natural history of adrenal incidentaloma in series of more than 25 patients with a mean follow-up of at least 12 months.

\begin{tabular}{lccccc}
\hline AUTHORS & No & $\begin{array}{c}\text { FOLLOW-UP } \\
\text { (months) }\end{array}$ & $\begin{array}{c}\text { SUBCLINICAL } \\
\text { CUSHING (n) }\end{array}$ & $\begin{array}{c}\text { OVERT } \\
\text { CUSHING (n) }\end{array}$ & $\begin{array}{c}\text { REGRESSION } \\
\text { (n) }\end{array}$ \\
\hline Terzolo et al., 1998 & 48 & 12 & 0 & 0 & 3 \\
Mantero \& Arnaldi, 2000 & 53 & $>12$ & 1 & 1 & 0 \\
Rossi et al., 2000 & 32 & $9-78$ & 1 & 0 & 0 \\
Grossrubatscher et al., 2001 & 53 & $6-78$ & 0 & 0 & 0 \\
Barzon et al., 2002 & 130 & $12-144$ & 5 & 4 & 0 \\
Libè et al., 2002 & 64 & $12-120$ & 0 & 0 & 0 \\
NISGAT, 2004 & 154 & $12-120$ & 4 & 0 & 4 \\
Bernini et al., 2005 & 115 & $12-84$ & nd & 0 & nd \\
TOTAL & $\mathbf{6 4 9}$ & & $\mathbf{1 1}(\mathbf{2 . 0} \%)$ & $\mathbf{5 ( 0 . 7 \% )}$ & $\mathbf{7}(\mathbf{1 . 3} \%)$ \\
\hline
\end{tabular}

autonomous cortisol secretion, its effect on long-term outcome and quality of life is not established $(3,46,47)$. Preliminary results suggest that adrenalectomy may benefit patients who have subclinical Cushing's syndrome, but these data should be confirmed in large prospective trials $(3,31)$. At the present time, there is insufficient evidence to recommend adrenalectomy to any patient who qualifies for subclinical Cushing's syndrome $(3,28,46)$. The decision between surgery and conservative management has to be considered individually on the basis of the physician's best clinical judgment and expertise as well as patient's preference. Surgery should be compared in terms of risk, cost, and outcome with the other possible interventions, including life-style changes and pharmacologic intervention. An optimal preventive measure should be harmless but this is not the case with adrenalectomy, even when performed by laparoscopic technique. Indeed, in experienced hands laparoscopic adrenalectomy has minimal (but not zero) morbidity and mortality, but experience is critical depending on a learning curve (48).

Most patients are not candidates for surgery and should be enrolled in a program of regular and careful follow-up to detect, treat, and control the manifestations of the metabolic syndrome. However, precise guidelines for follow-up of patients who do not undergo adrenalectomy have yet to be defined.

\section{REFERENCES}

1. Ross NS. Epidemiology of Cushing's syndrome and subclinical disease. Endocrinol Metab Clin North Am 1994;23:539-46

2. Grumbach MM, Biller BMK, Braunstein GD, Campbell KK, Carney JA, Godley PA, et al. Management of the clinically inapparent adrenal mass (incidentaloma). Ann Intern Med 2003;138:424-9.
3. Terzolo M, Bovio S, Reimondo G, Pia A, Osella G, Borretta $G$, et al. Subclinical Cushing's syndrome in adrenal incidentalomas. Endocrinol Metab Clin North Am 2005;34:423-39.

4. Feldkamp J, Santen R, Harms E, Aulich A, Mödder U, Scherbaum WA. Incidentally discovered pituitary lesions: high frequency of macro-adenomas and hormone-secreting adenoma results of a prospective study. Clin Endocrinol (Oxf) 1999;51:109-13.

5. Agha A, Liew A, Finucane F, Baker L, O'Kelly P, Tormey $W$, et al. Conventional glucocorticoid replacement overtreats adult hypopituitary patients with partial ACTH deficiency. Clin Endocrinol 2004;60:688-93.

6. Bondanelli M, Campo M, Trasforini G, Ambrosio MR, Zatelli MC, Franceschetti $P$, et al. Evaluation of hormonal function in a series of incidentally discovered adrenal masses. Metabolism 1997;46:107-13.

7. Boronat M, Moreno A, Ramon y Cajal S, Pineda E, Lucas T, Estrada J. Subclinical Cushing's syndrome due to adrenal myelolipoma. Arch Pathol Lab Med 1997; 121:735-7.

8. Terzolo M, Osella G, Alì A, Angeli A. Adrenal incidentalomas. In: De Herder WW (ed). Functional and Morphological Imaging of the Endocrine System. Endocrine Updates. vol. 7. Boston: Kluwer Academic Publishers, 2000. pp. 191-211.

9. Arnaldi $G$, Angeli $A$, Atkinson $A B$, Bertagna $X$, Cavagnini $F$, Chrousos GP, et al. Diagnosis and complications of Cushing's syndrome: A consensus statement. J Clin Endocrinol Metab 2003;88:5593-602.

10. Reincke M, Nieke J, Krestin GP, Saeger W, Allolio B, Winkelmann W. Preclinical Cushing's syndrome in adrenal incidentalomas: comparison with adrenal Cushing's syndrome. J Clin Endocrinol Metab 1992; 75:826-32

11. Ambrosi B, Peverelli S, Passini E, Re T, Ferrario R, Colombo $P$, et al. Abnormalities of endocrine function in patients with clinically silent adrenal masses. Eur $\mathbf{J}$ Endocrinol 1995;132:422-8.

12. Terzolo M, Osella G, Alì A, Borretta G, Cesario F, Paccotti $P$, et al. Subclinical Cushing's syndrome in adrenal incidentaloma. Clin Endocrinol (Oxf) 1998;48:89-97.

13. Caplan RH, Strutt PJ, Wickus GG. Subclinical hormone secretion by incidentally discovered adrenal masses. Arch Surg 1994;129:291-6.

14. Barzon L, Sonino N, Fallo F, Palu G, Boscaro M. Prevalence and natural history of adrenal incidentalomas. Eur J Endocrinol 2003;149:273-85.

15. Kloos RT, Gross MD, Francis IR, Korobkin M, Shapiro B. Incidentally discovered adrenal masses. Endocr Rev 1995; $16: 460-84$. 
16. Mansmann G, Lau J, Balk E, Rothberg M, Miyachi $Y$, Bornstein SR. The clinically inapparent adrenal mass: update in diagnosis and management. Endocr Rev 2004;25:309-40.

17. Osella G, Terzolo M, Borretta G, Magro G, Alì A, Piovesan $A$, et al. Endocrine evaluation of incidentally discovered adrenal masses (incidentalomas). J Clin Endocrinol Metab 1994;79:1532-9.

18. Terzolo M, Osella G, Alì A, Borretta G, Magro GP, Termine $A$, et al. Different patterns of steroid secretion in patients with adrenal incidentaloma. J Clin Endocrinol Metab 1996;81:740-4.

19. Flecchia D, Mazza E, Carlini M, Blatto A, Olivieri F, Serra G, et al. Reduced serum levels of dehydroepiandrosterone sulphate in adrenal incidentalomas: a marker of adrenocortical tumour. Clin Endocrinol (Oxf) 1995;42:129-34.

20. Bencsik Z, Szabolcs I, Kovács Z, Ferencz A, Vörös A, Kaszás I, et al. Low dehydroepiandrosterone sulfate (DHEA-S) level is not a good predictor of hormonal activity in nonselected patients with incidentally detected adrenal tumors. J Clin Endocrinol Metab 1996; 81:1726-9.

21. Bardet S, Rohmer V, Murat A, Guillemot C, Maréchaud R, Chupin $M$, et al. 131|-6- $\beta$-iodomethylnorcholesterol scintigraphy: an assessment of its role in the investigation of adrenocortical incidentalomas. Clin Endocrinol (Oxf) 1996;44:587-96.

22. Tsagarakis S, Vassiliadi D, Thalassinos N. Endogenous subclinical hypercortisolism: Diagnostic uncertainties and clinical implications. J Endocrinol Invest 2006; 29:471-82.

23. Trainer PJ, Grossman A. The diagnosis and differential diagnosis of Cushing's syndrome. Clin Endocrinol (Oxf) 1991;34:317-30.

24. Lavoie H, Lacroix A. Partially autonomous cortisol secretion by incidentally discovered adrenal adenomas. Trends Endocrinol Metab 1995;6:191-7.

25. Huizenga NA, Koper JW, De Lange P, Pols HA, Stolk RP, Burger $\mathrm{H}$, et al. A polymorphism in the glucocorticoid receptor gene may be associated with an increased sensitivity to glucocorticoids in vivo. J Clin Endocrirnol Metab 1998;83:144-51.

26. Mantero F, Terzolo M, Arnaldi G, Osella G, Masini AM, Alì $A$, et al. A survey on adrenal incidentaloma in Italy. J Clin Endocrinol Metab 2000;85:637-44.

27. Angeli A, Terzolo M. Adrenal incidentaloma - a modern disease with old complications [editorial comment]. J Clin Endocrinol Metab 2002;87:4869-71.

28. Chidiac RM, Aron DC. Incidentalomas. A disease of modern technology. Endocrinol Metab Clin North Am 1997;26:233-53.

29. Terzolo M, Pia A, Alì A, Osella G, Reimondo G, Bovio S, et al. Adrenal incidentaloma: a new cause of the metabolic syndrome? J Clin Endocrinol Metab 2002; 87:998-1003.

30. Terzolo M, Bovio S, Pia A, Conton PA, Reimondo G, DalI'Asta $C$, et al. Midnight serum cortisol as a marker of increased cardiovascular risk in patients with a clinically inapparent adrenal adenoma. Eur J Endocrinol. 2005; 153:307-15.

31. Tauchmanovà L, Rossi R, Biondi B, Pulcrano M, Nuzzo V, Palmieri EA, et al. Patients with subclinical Cushing's syndrome due to adrenal adenoma have increased cardiovascular risk. J Clin Endocrinol Metab 2002; 87(11):4872-8.

32. Ferranini E, Mari A. How to measure insulin sensitivity. J Hypertens 1998;16:895-906.

33. Reincke M, Fassnacht M, Väth S, Mora P, Allolio B. Adrenal incidentalomas: a manifestation of the metabolic syndrome? Endocr Res 1996;22:757-61.
34. Malik S, Wong ND, Franklin SS, Kamath TV, L'Italien GJ, Pio JR, et al. Impact of the metabolic syndrome on mortality from coronary heart disease, cardiovascular disease, and all causes in United States adults. Circulation 2004;110:1245-50.

35. Barzon L, Scaroni C, Sonino N, Fallo F, Gregianin M,

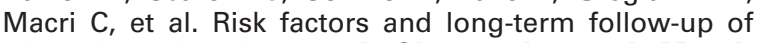
adrenal incidentalomas. J Clin Endocrinol Metab 1999;84:520-6.

36. Siren J, Tervahartiala P, Sivula A, Haapiainen R. Natural course of adrenal incidentalomas: seven-year follow-up study. World J Surg 2000;24:579-82.

37. Torlontano M, Chiodini I, Pileri M, Guglielmi G, Cammisa $\mathrm{M}$, Modoni $\mathrm{S}$, et al. Altered bone mass and turnover in female patients with adrenal incidentaloma: the effect of subclinical hypercortisolism. J Clin Endocrinol Metab 1999;84:2381-5.

38. Chiodini I, Torlontano M, Carnevale V, Guglielmi G, Cammisa $M$, Trischitta $V$, et al. Bone loss rate in adrenal incidentalomas: a longitudinal study. J Clin Endocrinol Metab 2001;86:5337-41.

39. Chiodini I, Tauchmanovà L, Torlontano M, Battista C, Guglielmi G, Cammisa M, et al. Bone involvement in eugonadal male patients with adrenal incidentaloma and subclinical hypercortisolism. J Clin Endocrinol Metab 2002;87:5491-4.

40. Hadjidakis D, Tsagarakis S, Roboti C, Sfakianakis M, Iconomidou V, Raptis SA, et al. Does subclinical hypercortisolism adversely affect the bone mineral density of patients with adrenal incidentalomas? Clin Endocrinol (Oxf) 2003;58:72-7.

41. Chiodini I, Guglielmi G, Battista C, Carnevale V, Torlontano M, Cammisa M, et al. Spinal volumetric bone mineral density and vertebral fractures in female patients with adrenal incidentalomas: the effects of subclinical hypercortisolism and gonadal status. J Clin Endocrinol Metab 2004;89:2237-41.

42. Libè R, Dall'Asta C, Barbetta L, Baccarelli A, Beck-Peccoz $\mathrm{P}$, Ambrosi B. Long-term follow-up study of patients with adrenal incidentalomas. Eur J Endocrinol 2002; 147:489-94.

43. Bernini GP, Moretti A, Oriandini C, Bardini M, Taurino C, Salvetti A. Long-term morphological and hormonal follow-up in a single unit on 115 patients with adrenal incidentalomas. Br J Cancer 2005;92:1104-9.

44. Young WF Jr. Clinical practice. The incidentally discovered adrenal mass. N Engl J Med 2007;356:601-10.

45. Shen WT, Lee J, Kebebew E, Clark OH, Duh OY. Selective use of steroid replacement after adrenalectomy: lessons from 331 consecutive cases. Arch Surg 2006;141:771-4.

46. Arlt W, Allolio B. Adrenal insufficiency. Lancet 2003;361:1881-93.

47. Aron DC. The adrenal incidentaloma: disease of modern technology and public health problem. Rev Endocr Metab Disord 2001;2:335-42.

48. Udelsman R. Adrenal. In: Norton JA, Bollinger RR, Chang $A E$, et al. (eds). Surgery: basic science and clinical evidence. New York: Springer-Verlag, 2001. pp. 897-917.

\section{Address for correspondence:}

Massimo Terzolo

Medicina Interna I

A.S.O. San Luigi, Regione Gonzole, 10

10043 Orbassano, Italy

Fax: ++ 390119038655

E-mail: terzolo@usa.net 